\title{
AP-de (地) Adverbs in Mandarin
}

\author{
Richard K. Larson \\ Stony Brook University
}

\begin{abstract}
Mandarin manner adverbs like dasheng 'loudly' (lit. 'big voice') occur both sentence-medially and sentence-finally, whereas adverbs formed with the adverbializer de (地) like kuaikuaide 'quickly' occur only sentence-medially. The behavior of AP-地 adverbs is puzzling under a classical adjunction analysis and under Cinque's (1999) hierarchy of functional projections. Here, I argue that Mandarin manner adverbs have a uniform low attachment in $\mathrm{V}$ complement position and that preverbal/medial position reflects obligatory movement imposed by the status of 地 as a "concordializing element".
\end{abstract}

\section{Keywords}

Mandarin, manner adverbs, case, concord

Studies in Chinese Linguistics, Volume 39, Number 1, 2018, 01-28 DOI: 10.2478/scl-2018-0001 (C2018 by T.T. $\mathrm{Ng}$ Chinese Language Research Centre, Institute of Chinese Studies, The Chinese University of Hong Kong 
Li and Thompson (1981) divide Mandarin adverbs into movable versus nonmovable forms. The temporal adverb jintian 'today', for instance, is classified as movable since it occurs both sentence-medially and sentence-initially (1a,b). By contrast, the temporal adverb yijing 'already' is classified as non-movable, since it occurs only sentence-medially $(2 a, b)$ :

(1) a. Ta jintian zou le.

3sg today leave ASP

'S/he left today.'

b. Jintian ta zou le.

(2) a. Ta yijing zou le.

3sg already leave ASP

'S/he already left.'

b. *Yijing ta zou le.

The subclass of Mandarin manner adverbs also includes both movable and nonmovable forms. For instance, dasheng 'loudly' (lit. 'big voice'/"big volume') is movable $(3 \mathrm{a}, \mathrm{b})$, whereas qiaoqiaode 'quietly' is non-movable $(4 \mathrm{a}, \mathrm{b})$.

(3) a. Ta zongshi hen dasheng gen bieren jianghua.

3 sg always very loud to others talk

'S/he always talks to others loudly.'

b. Ta zongshi gen bieren jianghua hen dasheng.

(4) a. Ta zongshi qiaoqiaode gen bieren jianghua.

3 sg always quiet-DE to others talk

'S/he always talks to others quietly.'

b. *Ta zongshi gen bieren jianghua qiaoqiaode.

Qiaoqiaode in (4) derives from the adjective qiao 'quiet' by suffixation of 地 (DE), comparable to the English form quietly, which derives from quiet by suffixation of -ly. Interestingly, Mandarin manner adverbs sharing qiaoqiaode's morphological derivation also share its distribution. AP-地 adverbs in Mandarin occur only sentence-medially, (5)-(8):

(5) a. Ta yanli-de zebei le wo.

3sg stern-DE reproach ASP I

'S/he reproached me sternly.'

b. *Ta zebei le wo yanli-de.

(6) a. Lisi gaoxing-de bangzhu le wo.

Lisi glad-DE help ASP I

'Lisi helped me gladly.'

b. *Lisi bangzhu wo gaoxing-de.

(7) a. Ta yinggai kuaikuai-de zuowan zuoye.

3sg should quick-DE finish homework

'S/he should finish her/his homework quickly.'

b. *Ta yinggai zuowan zuoye kuaikuai-de. 
(8) a. $\mathrm{Ni}$ yao hen xiaoxin(-de) kai che. you should very careful-DE drive car 'You should drive your car very carefully.'

b. *Ni yao kai che hen xiaoxin-de.

The distribution of AP-地 adverbs in Mandarin raises problems for current theories of adverbial modification. In this paper, I advance an analysis based on two main proposals. First, I argue that manner adverbs, in Mandarin and elsewhere, have a uniform low attachment position within vP/VP as complements of $\mathrm{V}$. This entails that sentence-medial position in Mandarin is always a derived one. Second, I propose that raising of AP-地 adverbs follows from the status of $\mathrm{DE}$ (地) as a concordializing element, which requires its associated phrase to occupy a position where case concord is possible. Sentence-final position is not one where concord is possible in Mandarin, as I show, whereas sentence-medial position is. Hence, the obligatory sentence-medial position of AP-地 adverbs. I begin with a review of the basic problems.

\section{The puzzle of AP-地}

AP-地 distribution in Mandarin is puzzling under the two most popular accounts of modifier syntax: the adjunct analysis and the functional head analysis.

\subsection{AP-地 adverbs as adjuncts}

Adverbs are often analyzed as V-projection adjuncts (see Tang 1990; Ernst 2002, Ernst 2014, among many others). Huang et al. (2009) adopt this view for Chinese manner adverbs, offering structure (10a) for (9a), where hen dasheng (identified as AP) is left-adjoined to V'. Presumably, this same analysis applies to (9b), with hen dasheng right-adjoined to $\mathrm{V}^{\prime}(10 \mathrm{~b}){ }^{1}$

(9) a. Ta hen dasheng chang minge. he very loud sing folk songs

'He sings folk songs loudly.'

b. Ta chang minge hen dasheng.

(10) a.

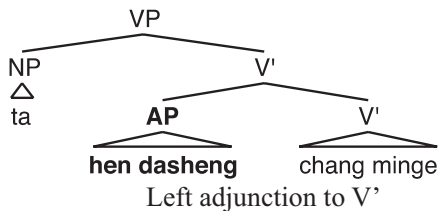

b.

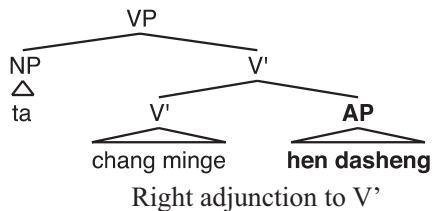

Ceteris paribus we expect the same distribution for manner AP qiaoqiaode 'quietly' under Huang et al.'s analysis. But although qiaoqiaode is allowed on the left (11a), it is excluded on the right (11b).

1 Huang et al. (2009) cite (9a) as fully acceptable. A number of Mandarin speakers I have consulted either prefer - de to be added to AP (see $34 \mathrm{a}$ below) or felt the example improved with a frequency adverb like zongshi 'always'. 
(11) a

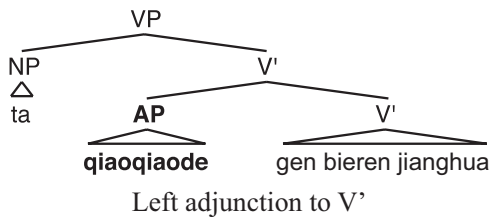

b. *

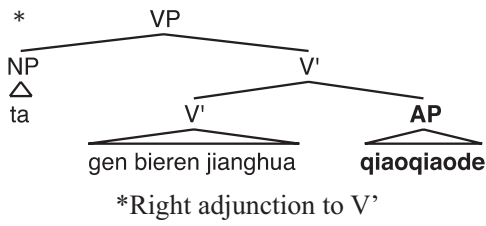

This asymmetry, observed with all AP-地 adverbs, is simply unexplained on the adjunction account.

\subsection{AP-地 adverbs as functional heads}

AP-地 adverb distribution is also puzzling under Cinque's (1999) analysis, wherein adverbs occur within a fixed hierarchy of functional projections (see also Laenzlinger 1996). Consider first (1)/(2) mentioned earlier. On a Cinque-style account, jintian and yijing might be analyzed as heads of a temporal location phrase (TLP) and a temporal priority phrase (TPrP), respectively, both projected between vP and TP (12a,b):

(12) a. Ta jintian yijing zou le. 3sg today already leave ASP

'He/she already left today.'

b.

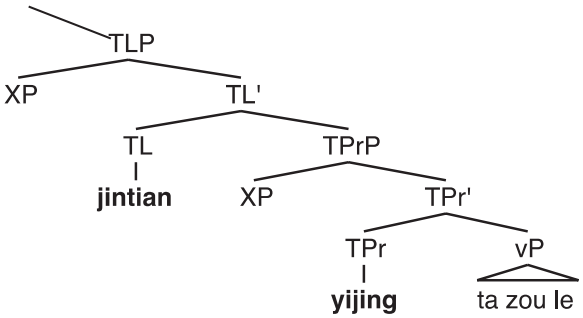

This proposal can capture the fixed order of jintian and yijing, together with their differing "mobility". Suppose yijing obligatorily raises the specifier of its complement (ta), but jintian makes raising an option. This will correctly predict (13a), where jintian occurs initially and yijing occurs medially, and (13b), where both occur medially. At the same time, it will exclude (13c), where both occur initially since ta has not raised:
a. $\left[_{\mathrm{TLP}}\right.$ jintian $\left[\mathrm{TPPP}_{\mathrm{T}}\right.$ ta yijing $\left[{ }_{\mathrm{VP}}\right.$ ta zou le $\left.\left.]\right]\right]$
Obligatory raising by yijing
b. $\left[_{\mathrm{TLP}}\right.$ ta jintian $\left[{ }_{\mathrm{TPPP}}\right.$ ta yijing $[\mathrm{VP}$ ta zou le $\left.\left.]\right]\right]$
Obligatory raising by yijing
c. $*\left[_{\mathrm{TLP}}\right.$ jintian $\left[_{\mathrm{TPP}}\right.$ yijing $\left[_{\mathrm{VP}}\right.$ ta zou le $\left.\left.]\right]\right]$ Optional raising by jintian *Non-raising

Crucially, Cinque's theory leads us to expect that adverbs of the same category and/or semantic class will pattern together. This expectation is certainly correct for TLPs. Mingtian 'tomorrow', zuotian 'yesterday', jinnian 'this year', qunian 'last year', mingnian 'next year', etc. all pattern identically to jintian. 
Consider now Chinese manner adverbs. Dasheng occurs sentence-medially and sentence-finally. Under Cinque's approach, we might analyze this by requiring dasheng to raise either the specifier of its complement $(t a)$ or the entire complement itself (ta chang ge):

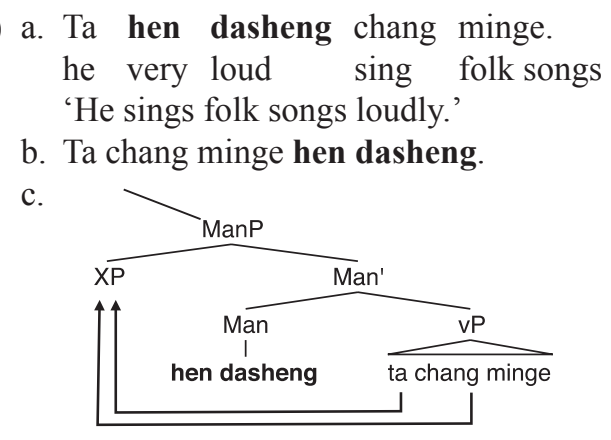

But 地-marked manner adverbs behave differently. 地-marked adverbs are blocked sentence-finally $(15 \mathrm{a}, \mathrm{b})$. Evidently, they must be required to raise only their complement specifiers and not their full complements (15c).

(15) a. Ta zongshi qiaoqiao-de gen bieren jianghua.

$3 \mathrm{sg}$ always quietly-DE to others talk

'S/he always talks to others quietly.'

b. *Ta zongshi gen bieren jianghua qiaoqiaode.

c.

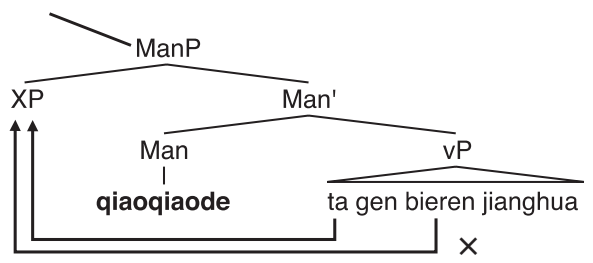

This entails that Man cannot be analyzed uniformly, unlike TL. Furthermore, the asymmetry in manner adverb behavior must somehow be traced to the properties of 地, given the uniform sentence-medial position for all 地-marked adverbs. 地 must somehow exclude whatever feature allows raising of $\mathrm{vP}$ with dasheng in (14c). It is unclear how 地 could act in this way.

\section{The position of manner adverbs}

Larson $(2004,2014)$ argues that, quite generally, manner adverbs project neither as $\mathrm{V}$-adjuncts nor as heads/specs of functional categories but instead as low $\mathrm{V}$ complements. $^{2}$ This view seems natural for English examples like (16a), where

2 See also Alexiadou (1997) and Stroik (1990, 1992a, 1992b) for related proposals. See Huang (1992), among many others for applications of "VP Shell" structures like (16) to Mandarin. 
the manner adverb is required by the verb (word/phrase). If the co-occurrence requirement is analyzed in the usual way, viz., as selection, then a structure like (16b) seems inevitable, counterpart to (16c), where the verb (put) selects a locative (Chomsky 1995, Larson 2014): ${ }^{3}$

(16) a. John worded/phrased the letter *?(carefully/tactfully/thoughtfully).

b.

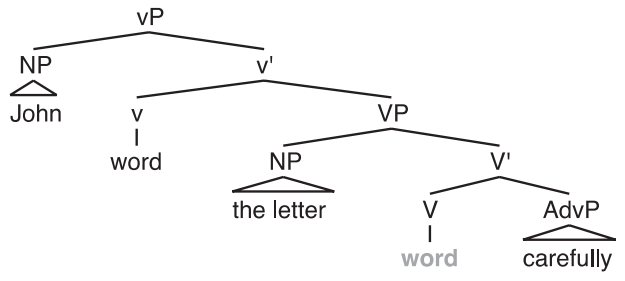

c.

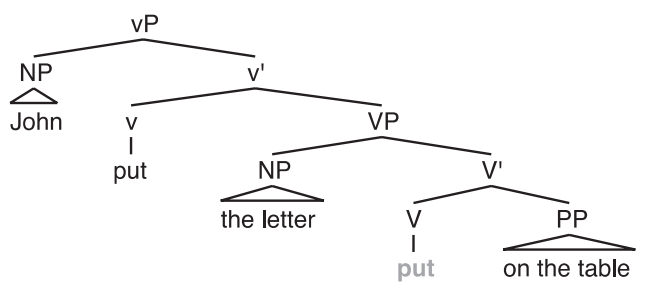

But in fact, evidence exists for a uniform low position for manner adverbs, even when the latter is not required or selected.

\subsection{Object-adverb asymmetries}

Stroik (1990) observes that domain asymmetries noted between objects and selected complements are also found with objects and adverbial adjuncts. Thus, alongside the selected dative complements in $(17 \mathrm{a}-\mathrm{d})$ and the selected locative complements in $(18 \mathrm{a}-\mathrm{d})$, Stroik notes $(19 \mathrm{a}-\mathrm{d})$, which involve unselected locatives and temporals, but which nonetheless appear fully comparable in behavior. On the basis of such facts, Stroik argues for a low attachment of such phrases, counterpart to that assigned to the manner AdvP and locative PP in (16a,b):

(17) a. i. John gave $\left[_{N P}\right.$ nothing $]\left[_{P P}\right.$ to any of the charities]. (NPI Licensing) ii. *John gave $\left[_{\mathrm{NP}}\right.$ anything] [ ${ }_{\mathrm{PP}}$ to none of the charities].

b. i. John gave $\left[_{N P}\right.$ the dogs] [ to each other's owner]. (Anaphor Binding) ii. *John gave $\left[_{\mathrm{NP}}\right.$ each other's dogs] $\left[_{\mathrm{PP}}\right.$ to the owners].

c. i. John gave $\left[_{\mathrm{NP}}\right.$ every award $]\left[_{\mathrm{PP}}\right.$ to its proper recipient $]$. (Q Binding) ii. *John gave $\left[_{\mathrm{NP}}\right.$ his award] $\left[_{\mathrm{PP}}\right.$ to every male recipient].

d. i. John gave $\left[_{\mathrm{NP}}\right.$ each dog] $\left[_{\mathrm{PP}}\right.$ to the other's owner]. (Each...the other) ii. *John gave $\left[_{\mathrm{NP}}\right.$ the other's dog] $\left[_{\mathrm{PP}}\right.$ to each owner].

3 In right-descending structures like (16a,b), selected elements (i.e., arguments) appear as both v/V specifiers (the letter) and complements (carefully/on the table). Assuming elements bearing oblique roles are projected lowest, these will occur as V-sisters (see Larson 2014 for further discussion). 
(18) a. i. John put $\left[_{\mathrm{NP}}\right.$ nothing] [anywhere nearby].

ii. *John put $\left[_{\mathrm{NP}}\right.$ anything] [ ${ }_{\mathrm{PP}}$ nowhere nearby].

b. i. John put $\left[_{N P}\right.$ the dogs] [ ${ }_{P P}$ in each other's kennels].

ii. *John put $\left[_{\mathrm{NP}} \text { each other's name tags }\right]_{\mathrm{PP}}$ on the dogs].

c. i. John put $\left[_{\mathrm{NP}}\right.$ every top] $\left[_{\mathrm{PP}}\right.$ on its proper bottle].

ii. * John put $\left[_{\mathrm{NP}}\right.$ its proper top] $\left[_{\mathrm{PP}}\right.$ on every bottle].

d. i. John put $\left[_{N P}\right.$ each dog] $\left[_{P P}\right.$ in the other's kennel].

ii. *John put $\left[_{\mathrm{NP}}\right.$ the other's name tag] $\left[_{\mathrm{PP}}\right.$ on each dog].

(19) a. i. John saw $\left[_{N P}\right.$ no one] [anywhere].

ii. *John saw $\left[_{\mathrm{NP}}\right.$ anyone] [nowhere].

b. i. I saw [ NP $_{\mathrm{N}}$ the men [somewhere near each other's homes].

ii. *I admired [ ${ }_{\mathrm{NP}}$ each other's sunsets] [those days].

c. i. I saw $\left[_{\mathrm{NP}}\right.$ everyone] [the day before he died].

ii. *I see $\left[_{\mathrm{NP}}\right.$ a man who plays Santa on it] [every Christmas].

d. i. I photographed [ ${ }_{\mathrm{NP}}$ each man] [somewhere near the other's home].

ii. *I photographed $\left[_{\mathrm{NP}}\right.$ a man from the other's city] [each place I stopped at].

Note now that both selected and unselected manner adverbials show the same behavior with respect to the relevant range of domain facts $(20 a-d)$ :

(20) a. i. John worded/wrote [ ${ }_{N P}$ no letter] [(in) any of the approved ways].

ii. *John worded/wrote $\left[_{\mathrm{NP}} \text { any letter }\right]_{\mathrm{PP}}$ (in) none of the approved ways].

b. i. John worded/wrote $\left[_{N P}\right.$ the letters] $\left[_{P P}\right.$ in each other's approved style].

ii. *John worded/wrote $\left[_{N P} \text { each other's greetings }\right]_{P P}$ in the styles of the authors].

c. i. John worded/wrote $\left[_{\mathrm{NP}}\right.$ every letter $]\left[_{\mathrm{PP}}\right.$ in its approved style].

ii. ${ }^{*}$ John worded/wrote $\left[_{\mathrm{NP}}\right.$ his greeting] $\left[_{\mathrm{PP}}\right.$ in the style of every author].

d. i. John worded/wrote $\left[_{N P}\right.$ each letter $]\left[_{P P}\right.$ in the other's approved style].

ii. *John worded/wrote $\left[_{\mathrm{NP}} \text { the other's greeting }\right]_{\mathrm{PP}}$ in the style of each author].

Therefore, if (17)-(19) give evidence for a uniform low attachment of their dative, locative, and temporal phrases, $(20 \mathrm{a}-\mathrm{d})$ would seem to do so also for a uniform low attachment of their manner phrases.

\subsection{Manner adverb incorporation}

Rivero (1992) observes that Modern Greek allows regular incorporation of manner (and directional) adverbials. (21a,b), for example, illustrates incorporation with férete 'behave', which requires a manner adverbial, like its counterpart predicate in English. $(22 \mathrm{a}, \mathrm{b})$ shows that the possibility of incorporation extends to vráso 'boil', with which a manner adverbial is entirely optional.

(21) a. I Maria férete kaka stin adelfi tis. DEF Mary behaves badly to+DEF sister hers

'Mary behaves badly to her sister.' 
$\begin{array}{lllll}\text { b. I Maria kakoférete } & \text { stin } & \text { adelfi tis. } \\ \text { DEF } & \text { Mary badly+behaves } & \text { to+DEF } & \text { sister } & \text { hers }\end{array}$

(22) a. To fagitó tha vrási.

the food FUT boil

'The food will boil.'

b. To fagitó tha vrási sigá.

'The food will boil slowly.'

c. To fagitó tha sigovrási.

The patterns in (21) and (22) are quite general in Modern Greek. Rivero (1992) gives the additional pairs in (23), which show manner adverbs incorporating into a broad range of verbs that would not normally be understood as selecting them: ${ }^{4}$

\begin{tabular}{|c|c|c|c|}
\hline Manner & Adv & Adv-V & (Rivero 19 \\
\hline a. argá & 'slowly' & argomasó & '(I) chew slowly' \\
\hline b. dískola & 'hard' & diskologenó & 'give birth with difficulty' \\
\hline c. gorgá & 'fast' & gorgopetó & 'fly fast' \\
\hline d. kaká & 'badly' & kakologó & 'talk badly' \\
\hline e. kalá & 'well' & kalovlépo & 'see well' \\
\hline f. krifá & 'secretly' & krifogeló & 'chuckle' \\
\hline g. psilá & 'lightly' & psilozalízome & 'feel slightly dizzy' \\
\hline h. sfixtá & 'tightly' & sfixtangaliázo & 'embrace tightly' \\
\hline i. sigá & 'softly' & sigotragudó & 'sing softly' \\
\hline j. stravá & 'slanted' & travokitó & 'look sideways' \\
\hline
\end{tabular}

Manner adverb incorporation is not peculiar to Modern Greek. Similar facts have been reported for a range of other languages, including Mazatec (Capen 1995) and Nahuatl (Langacker 1979). ${ }^{5}$

Baker (1988) argues that syntactic incorporation requires the headcomplement relation as a condition of well-formedness (24).

$$
\left[{ }_{\mathrm{V}}, \mathrm{V}\left[_{\mathrm{AdvP}} \mathrm{Adv}\right]\right] \rightarrow\left[_{\mathrm{V}}, \operatorname{Adv}-\mathrm{V}\left[_{\mathrm{AdvP}} \mathrm{Adv}\right]\right]
$$

4 The phenomena noted by Rivero are argued by Drachman and Malikouti-Drachman (1992) and Smirniotopoulos and Joseph (1997) to be instances of compounding rather than incorporation. But Alexiadou (1997) argues convincingly that the examples in (17b), (18c) and (19a-d) represent true syntactic incorporation.

5 Thus, Capen (1995) gives the synonymous pair in (ia,b) from Chiquihuitlán Mazatec; (ia) contains the free manner adverb ndaha 'well' (cf. 23e), and (ib) contains its incorporated counterpart $n d u h u$. Note the latter shows second person plural marking, indicating that it is part of the verb stem.

(i) a. Mehe -ræ ši visekun ndaha yase væ, hemu čo 'o sekun. need $=3$ COMPL stand $=2 \mathrm{pl}$ well post that very bad stand 'It is necessary that you position that post well; it is not secure.'

b. Mehe -ræ ši visekun-nduhu yase væ, hemu čo 'o sekun. need $=3$ COMPL stand $=2$ pl-well $=\mathbf{2 p l}$ post that very bad stand 
If Baker is correct, this implies the head-complement configuration for all the manner adverbs in (21)-(23), including examples where the adverb is nonselected according to the usual tests.

\subsection{Generic interpretation and the mapping hypothesis}

Middle constructions typically require a postverbal predicate (adverb or adjunct PP) and are perceived as odd or somehow incomplete without one (25a-c) (Roberts 1987). Why is this so?

(25) a. These flowers grow \#(quickly)

b. Bread cuts \#(easily)

c. The clothes iron \#(well)

Condoravdi (1989) offers an interesting and intuitively appealing semantic explanation. She proposes that middles involve structured, generic event quantification, as shown in $(26 \mathrm{a}-\mathrm{c})$, which correspond to $(25 \mathrm{a}-\mathrm{c})$, respectively.

(26) а. $\Gamma \mathrm{e}[\mathrm{Con}(\mathrm{e}) \&$ growing(f, e)] (quick(e))

("Generally, for contextually relevant events involving the growing of these flowers, those growings are quick.")

b. $\Gamma \mathrm{e}[\mathrm{Con}(\mathrm{e}) \&$ cutting(br, e)] (easy(e))

("Generally, for contextually relevant events involving the cutting of this (kind of) bread, those cuttings are easy.")

c. $\Gamma \mathrm{e}[\mathrm{Con}(\mathrm{e}) \&$ ironing $(\mathrm{c}, \mathrm{e})]$ (well(e))

("Generally, for contextually relevant events involving the ironing of the clothes, those ironings turn out well.")

Here $\Gamma$ is the generic quantifier. The main clause material supplies the restriction on the generic event quantification, with its content presupposed or background entailed. By contrast, the sentence-final adjunct supplies the quantificational scope, with its content understood as asserted. Condoravdi's proposal affords a surprising answer to the questions of why the adjuncts in $(25 \mathrm{a}-\mathrm{c})$ are perceived as required and why the sentence feels incomplete without them. The adjunct is required because in generic quantification of this kind, it constitutes the main predicate semantically. It supplies what the sentence is fundamentally asserting: that something is/occurs quick, easy, well, etc.

Condoravdi's semantic proposal seems fully applicable to the much broader class of generic quantifications and not just middles. Consider (27ai-ci), for instance. In all these cases, the same information partition into restriction and scope seems appropriate (27aii-cii):

(27) a. i. Olga dances beautifully.

ii. $\Gamma \mathrm{e}[\operatorname{Con}(\mathrm{e}) \&$ dancing $(\mathrm{o}, \mathrm{e})]$ (beautiful(e))

("Generally, for contextually relevant events involving Olga dancing, those dancings are beautiful.") 
b. i. John writes letters carefully.

ii. Гe[ Con(e) \& writing(j, l, e)] (careful(e))

("Generally, for contextually relevant events involving John writing letters, those writings are beautiful.")

c. i. Alice donates money to charities cheerfully.

ii. $\Gamma \mathrm{e}[\operatorname{Con}(\mathrm{e}) \&$ donating(a,m,c,e)] (cheerful(e))

("Generally, for contextually relevant events involving Alice donating money to charities, those donations are cheerful.”)

Diesing (1992) proposes a mapping hypothesis that matches up the parts of quantificational structure with syntactic position. In brief, high material (IP) is mapped to the quantifier restriction, whereas low material (VP) is mapped to the quantificational scope. Larson (2004) adopts a variant of the mapping hypothesis essentially due to Chierchia (1995):

Mapping hypothesis: Lowest material from VP is mapped to the nuclear scope.

The residue is mapped into a restrictive clause.

Note that under the mapping hypothesis, Condoravdi's semantic proposal implies a low position for manner adverbs in generics, including middles, since the adjunct represents the quantificational scope, as discussed earlier (28):

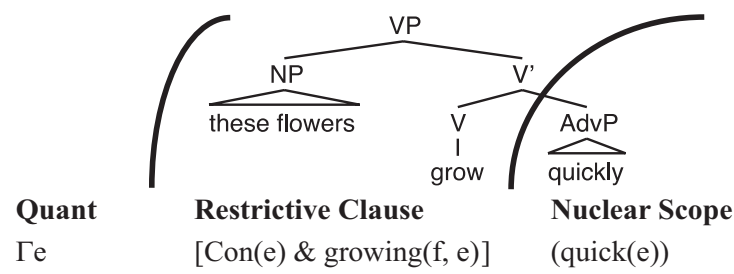

In fact, taking Condoravdi's semantic together with Diesing's mapping hypothesis, generics become a revealing probe into structure. The predicate understood as the nuclear scope (the main assertion) should be analyzed as the lowest phrase in vP/VP: ${ }^{6}$

6 McConnell-Ginet (1994) notes examples like This silk washes and This dress buttons as apparent exceptions to the generalization that middles require a postverbal predicate; similar exceptions occur with negation, e.g., This bread doesn't cut. All of these appear to involve focus on the final VP, which is well-known to correlate with assertion (Herburger 2000). Hence, for example, This silk washes plausibly involves a generic representation as in (ia), where the contextually relevant actions (the restriction) are presumably cleanings and where what is asserted about the relevant events (the scope) is that they are washings. Note that this logical form correlates with the unaccusative character of wash under the mapping hypothesis, since the object, understood as part of both the presupposition and the assertion, originates within the low VP and raises (ib).

(i) a. Ге[ Con(this silk,e)] (washing(this_silk,e))

"Generally, for contextually relevant actions with this silk, they are washings."

(i.e., 'what one does with this silk with respect to cleaning it is wash it.' etc.)

b. This silk | [ ${ }_{\mathrm{VP}}$ washes this silk].

Restr.

Scope 
(29)

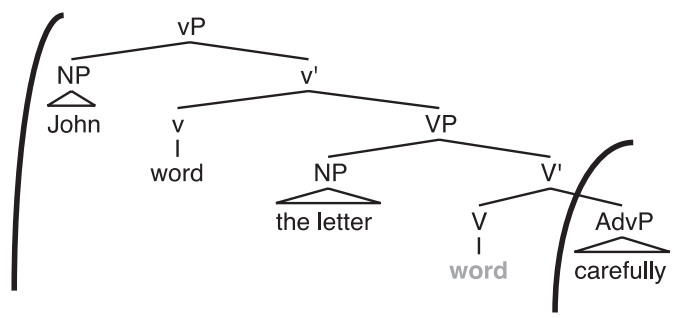

$\begin{array}{lll}\text { Quant } & \text { Restrictive Clause } & \text { Nuclear Scope } \\ \Gamma \mathrm{e} & {[\mathrm{Con}(\mathrm{e}) \& \operatorname{writing}(\mathrm{j}, 1, \mathrm{e})]} & (\operatorname{careful}(\mathrm{e}))\end{array}$

\section{Manner adverb position in Mandarin generics}

Mandarin speakers report a strong postverbal preference for manner adverbials in generic sentences (30). Preverbal position favors an episodic interpretation as opposed to a generic one (31).

(30) a. Lisi jiang-hua hen dasheng.

Lisi talk very big-voice

'Lisi (always) talks loudly.'

b. Ta zoulu hen xiaosheng.

3 sg walk very little-voice

'S/he (always) walks very quietly.'

c. Zhe-xie hua zhang(-de) hen kuai.

these flower grow(-de) very fast

'These flowers grow quickly; the growing of these flowers is quick.'

(31) a. Zhangsan qiaoqiao-de shuo hua.

'Zhangsan is speaking quietly.'/??'Zhangsan speaks quietly.'

b. Lisi kuaikuai-de zoulu.

'Lisi is walking quickly.'/??'Lisi walks quickly.'

Read as generics, something seems to be "missing" in $(31 \mathrm{a}, \mathrm{b})$, as in the corresponding English cases in (21).

These data are straightforward under the proposals in Section 2. (30a-c) are analyzable in terms of a low position for the manner adverbial, as expected under the mapping hypothesis (32).

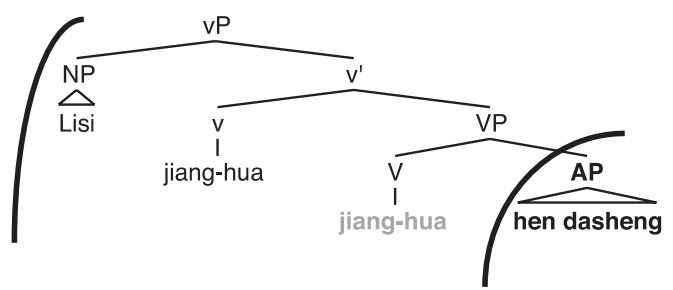

$\begin{array}{lll}\text { Quant } & \text { Restrictive Clause } & \text { Nuclear Scope } \\ \Gamma \mathrm{e} & {[\text { Con }(\mathrm{e}) \& \text { talking }(1, \mathrm{e})]} & (\operatorname{loud}(\mathrm{e}))\end{array}$


By contrast, $(31 \mathrm{a}, \mathrm{b})$ will be problematic given the high position of qiaoqiaodel kuaikuaide (33):

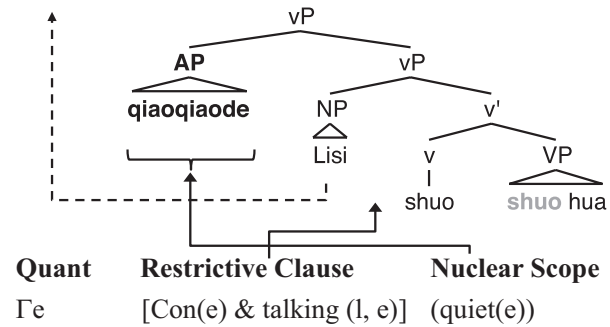

(33) not only violates the mapping hypothesis; the syntax-semantics mapping we observe is actually the opposite of what we expect: the upper portion of the clauses associates with the nuclear scope and the lower part with the restrictive clause.

Nonetheless, Mandarin does show generics with manner adverbials in preverbal position; the presence of postverbal material or an explicit quantificational adverb seems to aid this interpretation (cf. 35a,b):
a. Zhangsan zixi-de zuo shi.
Zhangsan meticulous-DE do work
'Zhangsan does work meticulously.'

b. Zhe-ge mianbao hen hao/rongyi qie.

this bread very good/easy cut

'This bread cuts well/easily.'

(35) a. Lisi changchang/zongshi qiaoqiao-de shuo hua.

Lisi always quiet-DE speak word

'Lisi always speaks quietly.'

b. Lisi changchang/zongshi kuaikuai-de zou guo dating.

Lisi always quick-DE walk through hallway

'Lisi always walks through the hallway quickly.'

But now our problems with the mapping hypothesis return. The mapping once again comes out backward (36). What is going on?

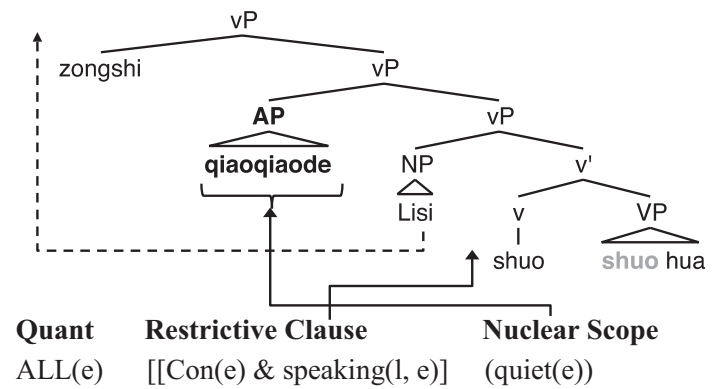


Suppose that Mandarin manner adverbials project uniformly into low position (32) but AP-地 forms obligatorily raise leftward to the vP edge. The mapping hypothesis could then be satisfied unproblematically by always interpreting the lower copy of AP (37).

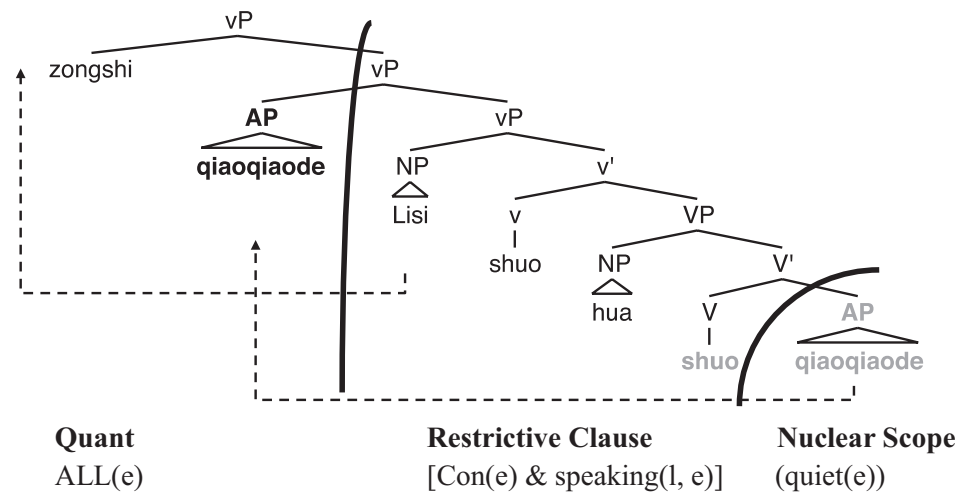

This proposal would essentially invert the view of Li and Thompson (1981), with which we began. Rather than being non-moveable, AP-地 manner adverbs would be distinguished as always moving from a sentence-final to a sentence-medial site (cf. *Lisi zongshi shuo hua qiaoqiao-de).

A movement account reconciles the position of AP-地 adverbs in generics with the mapping hypothesis. But it also raises immediate questions, viz., why is movement required with AP-地 adverbs? Why is low complement position forbidden specifically with manner adverbials of this class?

\section{Mandarin AP-地 as concordial}

\subsection{The categorical structure of moveable manner adverbials}

In influential work, Li $(1985,1990)$ observed that adjuncts occurring in postverbal position in Mandarin are invariably nominal in character. Thus, Mandarin

7 An anonymous SCL reviewer notes the resemblance between (35a) (with 'always') and (i), which involves a second instance of $\mathrm{V}$ (shuo) but no noticeable difference in meaning:

(i) Lisi shuo hua zongshi qiaoqiao-de shuo (*hua).

Lisi speak word always quiet-DE speak word.

'Lisi always speaks quietly.'

Despite similar interpretations, the relation between (i) and (35a) is not straightforward. Thus, (i) has a further variant containing what is apparently an independent subject $t a$ (i'):

(i') Lisi shuo hua ta zongshi qiaoqiao-de shuo (*hua).

Lisi speak word $\mathbf{3 s g}$ always quiet-DE speak word.

'Lisi always speaks quietly.'/'When Lisi speaks he speaks quietly.'

Hence, (i) cannot simply be a version of (35a) with the lower V copy spelled out (a conclusion already implied by the relative order qiaoqiao-de - shuo in (i)/(i') cf 37). I leave the relation between the two examples for future exploration. 
permits postverbal adjunct phrases of frequency and duration, since these have the structure of NPs $(38 \mathrm{a}, \mathrm{b})$, but adjunct PPs are typically disallowed postverbally (38c). The latter must occur in preverbal position (38d). ${ }^{8}$

(38) a. Ta kesou [ ${ }_{\mathrm{NP}}$ liang ci ]. 3 sg cough two times

'He/she coughed twice.'

b. Ta kesou le $\left[_{\mathrm{NP}}\right.$ liang fenzhong]. 3 sg cough two minutes

'He/she coughed for two minutes'.

c. ${ }^{*}$ Ta xi gou [pp zai gongyuan li ]. 3sg wash dog in park interior 'He/she washed the dog in the park.'

d. Ta $\left[_{\mathrm{PP}}\right.$ zai gongyuan li] xi gou.

Interestingly, despite their apparent status as APs, indicated by the presence of the degree element hen 'very', many moveable manner adverbs that are permitted postverbally also exhibit nominal substructure $\left[_{\mathrm{AP}} \mathrm{X} \mathrm{N}\right]$. Consider $(39 \mathrm{a}-\mathrm{f})$ :
a. Ta chang minge hen dasheng.
he sing folk songs very loudly
'He sings folk songs loudly.'

b. Ta kaiche hen xiaoxin.

he drive very carefully

'He drives carefully.'/'He drives with care.'

c. Ta zuoshi hen qinfen.

he work very diligently

'He works diligently.'/'He works with diligence.'

d. Ta huida wenti hen naixin.

he answer question very patiently

'He answers questions patiently.'/'He answers questions with patience.'

e. Ta gongzuo hen xinku.

he work very hard

'He works hard.'/'He works with effort.'

f. Ta duidai bieren hen zhencheng.

he treat others very sincerely

'He treats others sincerely.'/"He treats others with sincerity.'

8 An anonymous SCL reviewer prefers (i-ii) in the following to (38a,b), respectively, in the text. But examples like $(38 \mathrm{a}, \mathrm{b})$ can be readily found in the CCL Corpus, so I will assume that the latter are also acceptable.

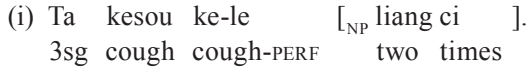
'He/she coughed twice.'
(ii) $\mathrm{Ta}$ kesou ke-le $\quad[$ liang fenzhong].
3sg cough cough-PERF two minutes
'He/she coughed for two minutes.'

I am grateful to Liu Lei for the CCL corpus search results. 
Dasheng 'loudly' in (39a) contains sheng 'voice' (N) and literally means 'big voice'; similarly for xiaosheng 'quietly' (lit. 'little voice'). Xiaoxin 'care' in (39b) contains xiao 'small' and xin 'heart' (N). Qinfen 'diligently' in (39c) contains qin 'industrious' and fen '??'. Naixin 'patiently' in (39d) contains nai 'endure' and xin 'heart' (N). Xinku 'hard' in (39e) contains xin 'spice' (N) and ku 'bitterness' (N). Zhencheng 'sincerely' in (39f) contains zhen 'true' and cheng 'honesty' (N). These items are thus somewhat reminiscent of English complex forms like in case of, in spite of, and because of, which, despite their status as prepositions (Emonds 1976, Emonds 1985), contain nominal substructure, as signaled by the preceding and trailing prepositions (in/by and of) (40): $: 10$

(40) a. $\left[_{\mathrm{P}}\right.$ in $\left[_{\mathrm{N}}\right.$ case $]$ of $]$

b. $\left[_{\mathrm{P}}\right.$ in $\left[_{\mathrm{N}}\right.$ spite $]$ of $]$ (cf. $\left[_{\mathrm{P}}\right.$ despite $]$ )

c. ${ }_{\mathrm{P}}$ because of $]$, historically $\left[_{\mathrm{P}}\right.$ by $\left[_{\mathrm{N}}\right.$ cause $]$ of $]$ )

The moveable manner adverbs in (39) always allow, and typically either prefer or require, 地-marking sentence-medially. But as with other manner adverbs, they are forbidden with 地-marking sentence-finally. Compare (39a-f) and (41a-f): ${ }^{11}$

(41) a. Ta dasheng ??(-de) chang minge/chang minge dasheng(*-de).

b. Ta xiaoxin ??(-de) kaiche/kaiche xiaoxin(*-de).

c. Ta qinlao ??(-de) zuoshi/zuoshi qinlao(*-de).

d. Ta zongshi naixin ??(-de) huida wenti/huida wenti hen naixin(*-de).

e. Ta xinku ??(-de) gongzuo/gongzuo xinku(*-de).

f. Ta zhencheng ??(-de) duidai bieren/duidai bieren zhencheng(*-de).

9 The examples in $(40 \mathrm{a}-\mathrm{c})$ make clear that active status of the nominal core in these Ps is not a matter of headedness. The head of these constructions is clearly $\mathrm{P}$, which does not trigger the genitive.

10 It must be noted that the nominal character of Mandarin manner adverbs occurring in postnominal position is less clear in certain cases. Chong Zhang (personal communication) points out that boldfaced items in (i)-(iii) below appear to derive from other categories.
(i) a. Ta zuoshi hen jinshen.
$>$ jin ('cautious') shen ('cautious') $\mathrm{A}+\mathrm{A}$
he work very cautious
'He works cautiously.'

b. Ta jinshen-de zuoshi.

(ii) a. Ta miandui tiaozhan hen yonggan. > yong ('courage') gan ('dare') A+V

he face challenges very courageous

'He faces challenges courageously.'

b. Ta yonggan-de miandui tiaozhan.

(iii) a. Ta xiezi hen liaocao.

he write very messily

'He writes (characters) messily.'

b. Ta liaocao-de xiezi.

I have no account of these forms at present.

11 The judgments in (41) show apparently some variation according to construction and speaker. An anonymous SCL reviewer notes that xiaoxin kaiche (without de) 'carefully drive-car' is fully acceptable as an imperative sentence (cf. 41b). Furthermore, he/she finds xinku gongzuo 'hard work' generally acceptable in medial position without de. (Ta xinku gongzuo-le liang tian. 'S/he worked hard for two days.') (cf. 41e). 
The pattern is thus that whereas DE (地) typically enables pre-V occurrence, it prohibits post-V occurrence. Li $(1985,1990)$ proposes that postverbal nominal adjuncts are case-licensed in that position. If this is correct, then 地's effect on adverb distribution is plausibly related to case.

\subsection{Case assignment vs. case concord}

Traditional grammars standardly describe nouns as being inflected for case and $\varphi$-features and attributive elements (including articles and adjectives) as agreeing with them or exhibiting "concord". Thus, in the Icelandic nominal in (42) (from Kester 1996), kennigar 'theories' is inflected as a feminine plural nominative, and the preceding determiner and adjectives agree with it:

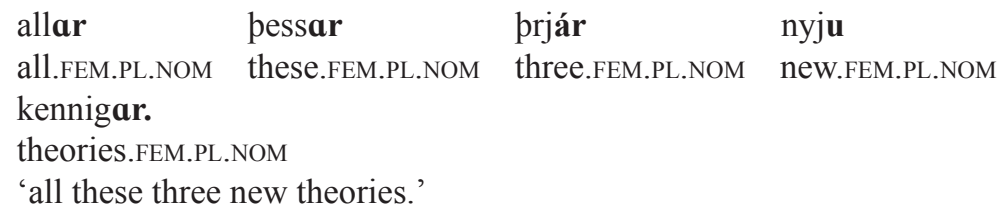

Describing things this way draws an implicit distinction in the inflectional morphology observed in (42). In effect, inflection is analyzed as "real" on N, but derivative on the other elements, present only as concord (43).

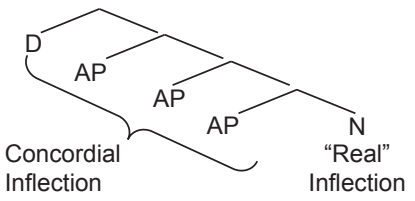

This traditional view accords rather well with modern syntactic analyses that see case as reflecting a relation between a higher "probe" and a lower "goal," wherein the former scans its c-command domain, probing for the inflectional values on its goal $(\mathrm{N})$ and agreeing with various elements on the path between them. With nominative case, the probe is assumed to be a higher finite $\mathrm{T}$, which scans its c-command domain for a nominative-marked noun, agreeing with Ds and APs "on the way down," until its search finally terminates with N (44a). A similar picture holds for accusative case, whose probe is a little v (44b):

(44) a.

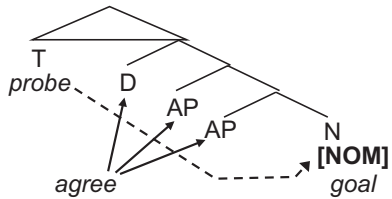

b.

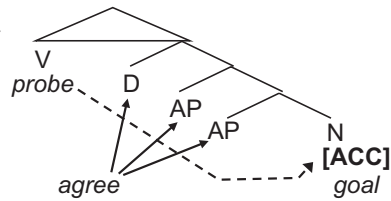

Note that on this picture, a potentially agreeing element $\alpha$ (D, AP, etc.) must occur lower than the probe (T or v) and higher than the goal (N) (45a). If $\alpha$ occurs hierarchically above the probe, it will lie outside the latter's scanning domain 
(45b). If it occurs hierarchically below the goal, the probe's scan will terminate before $\alpha$ is reached, depriving it of agreement (45c):
a. $[\mathrm{T} / \mathrm{v} \ldots[\alpha \ldots[\ldots \mathrm{N}]]$
b. $[\alpha \ldots[\mathrm{T} / \mathrm{v} \ldots \mathrm{N}] \ldots \alpha]$
( $\alpha$ lies outside T/v's domain)
c. $[\mathrm{T} / \mathrm{v} \ldots[\ldots \mathrm{A} \ldots[\ldots \alpha]]$
(scan terminates before reaching $\alpha$ )

Summarizing, then, agreeing items must occur in the c-command domain lying between the probe and goal.

\section{3 地 as "concordializer"}

Interestingly, languages seem to have devices for converting items that are valued for case to ones that merely agree for case. Certain Slavonic languages, for example, contain suffixes for creating so-called "possessive adjectives" from nouns (Corbett 1987). Thus, in addition to familiar postnominal genitives (46a), Upper Sorbian (spoken in Lusatia, eastern Germany) exhibits possessive adjectives, formed by suffixing -in/-yn to feminine nouns and -ow to masculine nouns (46b).
a. 'kniha Jan-a book Jan-GENSG 'a/the book of Jan's.'
b. Jan-ow-a knih-a
Jan-POSS-NOMSGFEM book-NOMSGFEM
'Jan's book.'

Upper Sorbian (Corbett 1987)

As discussed by Corbett (1987), the possessive Janowa in (46b) is fully adjectival in behavior, exhibiting the same agreement forms as attributive adjectives (here agreeing with the nominative, feminine singular head knih-a 'book') and in preceding the head. ${ }^{12}$

Suppose that Mandarin 地, like Upper Sorbian -in/-yn/-ow, essentially creates a "concordial" or adjectival element - more precisely, an element requiring case but able to receive it only by agreement. This would compel raising to a position between a case probe (e.g., T) and a goal (e.g., Lisi) (47).

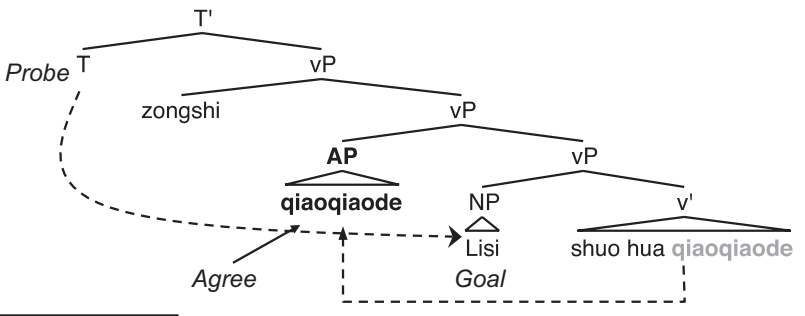

12 Note that in (46b), the gender marked on the possessive adjective (FEM) disagrees with that of the noun stem Jan (MASC). This illustrates clearly the agreement nature of the inflection. 


\subsection{Case features and agreement (Pesetsky and Torrego 2007)}

The proposal just offered can be worked out technically using recent theories of features, which draw a distinction according to whether instances of features $\mathrm{F}$ are interpretable, valued or neither (i.e., uninterpretable-unvalued). Broadly speaking, this move imports the PF-LF distinction into features (or, more precisely, instances of them). Thus, interpretable instances of features, notated "iF", are ones associated with "meaning" - i.e., with instructions to the conceptual-intentional system (48a). Valued instances of features, notated "Fval", are ones associated with "pronunciation" - i.e., with instructions to the system of expression (48b). Uninterpretable-unvalued instances of features, here notated simply "F", are concordial (48c) - i.e., they have no independent LF content and whatever pronounced content they have is derivative on their relation to a valued feature.

(48) a. iF interpretable $\mathrm{F}$, associated with a "meaning"

b. Fval valued $F$, associated with visible marking/pronunciation

c. $\mathrm{F}$ uninterpretable-unvalued $\mathrm{F}$, concordial

Under the theory of features in Pesetsky and Torrego (2007), unvalued instances of features (iF or F) probe their c-command domain seeking to agree with another instance of F. In order for a feature F to be "legible" at the interfaces, it must have both interpretable and valued instances linked by agreement. Thus, all of (49ac) will constitute legible features since all represent a set of instances linked by agreement (signified by "[n]") and all contain both an interpretable instance of $F$ and a valued instance of $F$. By contrast, none of (50a-e) will constitute legible features since one or more of the required conditions - presence of an interpretable instance, presence of valued instance, or linking by agreement fails to hold:
a. $i F[n] \ldots F v a l[n]$
b. $\mathrm{iF}[\mathrm{n}] \ldots \mathrm{F}[\mathrm{n}] \ldots \mathrm{Fval}[\mathrm{n}]$
c. $\mathrm{iF}[\mathrm{n}] \ldots \mathrm{F}[\mathrm{n}] \ldots \mathrm{F}[\mathrm{n}] \ldots \mathrm{Fval}[\mathrm{n}]$

(50) a. $\mathrm{iF}[\mathrm{]}]$

b. $\mathrm{iF}[\mathrm{n}] \ldots \mathrm{F}[\mathrm{n}]$

c. Fval[ ]

d. $\mathrm{F}[\mathrm{n}] \ldots \mathrm{Fval}[\mathrm{n}]$

e. $\mathrm{iF}[\mathrm{F}$... Fval[ ]

As an illustration of these proposals in the domain of case, consider (51a) from German, containing the transitive verb küssen 'kiss' and an object showing multiple instances of accusative agreement. Chomsky (1995) analyzed $\mathrm{v}$ as the source of accusative case. Under Pesetsky and Torrego (2007), v can be analyzed as bearing an interpretable, unvalued accusative feature (iACC), which probes for a valued, uninterpretable instance of the same feature (ACCval) on the object noun (Mädchen). The determiner (das) and the adjective (hübsche) are concordial for this feature, i.e., they bear instances of [ACC] that are neither interpretable nor 
valued. Assuming that the derivation proceeds bottom-up as in (51b), unvalued [ACC] on hübsche first probes [ACCVal] on Mädchen and, upon merger, agrees with it (1). Unvalued [ACC] on das then probes [ACC] on hübsche and agrees with it on merger (2). Finally, unvalued [iACC] on v probes [ACC] on das and agrees with it when $\mathrm{V}$ and VP are merged (3), yielding a feature structure corresponding to (49c), which is legible, as we noted.

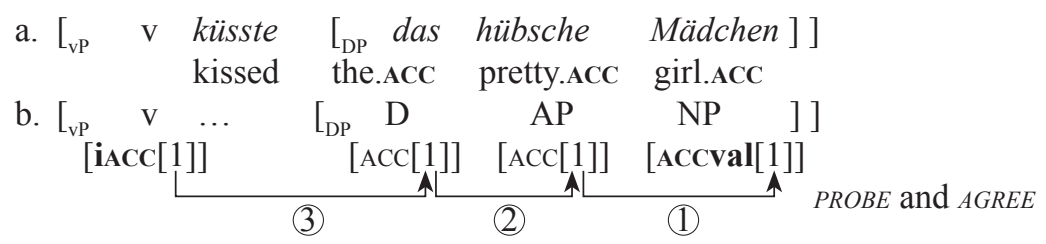

\subsection{Mandarin manner adverbs}

The apparatus sketched above can be directly applied to Mandarin, including the AP-地 adverbials we are concerned with here. Consider first a simple transitive like (52a). In line with previous discussion, I assume that $\mathrm{T}$ bearing an interpretable instance of NOM agrees with the subject $t a$ 'he/she' bearing a valued instance of NOM. Similarly, little v bearing an interpretable instance of ACC agrees with the direct object niu-rou mian 'beef noodles' bearing a valued instance of $\operatorname{ACC}(52 b)$.

(52) a. Ta chi le niu-rou mian.

he eat PERF beef noodles

'He ate beef noodles.'

b. $\left[{ }_{\mathrm{T}}, \mathrm{T} \quad\left[_{\mathrm{vP}}\right.\right.$ ta $\left[_{\mathrm{v}}, \mathrm{v} \quad\left[_{\mathrm{VP}}\right.\right.$ chi $\left[_{\mathrm{NP}}\right.$ niu-rou mian $\left.\left.\left.]\right]\right]\right]$ inOM[1] NOMval[1] iACC[2] ACCval[2]

AGREE!

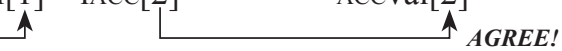

LEGIBLE!

I propose essentially the same analysis for an intransitive containing a subject and a nominal postverbal manner adverb (53a). $\mathrm{T}$ bearing an interpretable instance of NOM agrees with the subject $t a$ 'he/she' bearing a valued instance of NOM. Here, however, little $\mathrm{v}$ bearing an interpretable instance of ACC agrees with the nominal adverb dasheng 'loudly' (53b). In effect, the latter behaves as an adverbial object.

(53) a. Ta jiang-hua dasheng.

he speak-word loud

'He speaks loudly.'

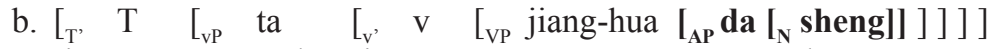
iNOM[1] NOMval[1] iACC[2] ACCVal[2] AGREE!

AGREE! LEGIBLE!

Now suppose the effect of suffixing 地 'de' to a Mandarin nominal adverbial is to create an exclusively concordial element: an expression able to agree for 
case and hence unable to be valued for it, counterpart to the Slavonic possessive adjectivalizing elements noted earlier (54):

$$
\left.\begin{array}{rl}
{\left[_{\mathrm{AP}}\right.} & \alpha
\end{array}\right] \quad \Leftrightarrow \quad\left[\begin{array}{c}
\left.{ }_{\mathrm{AP}} \alpha-\text { 地 }\right] \\
\operatorname{CASE}[]
\end{array}\right.
$$

It follows that suffixing 地 to dasheng 'loud' in (53a) will no longer yield an LFlegible case feature. Although little v bearing an interpretable ACC can agree with the adverb, the ACC feature will not end up valued as a result (55).

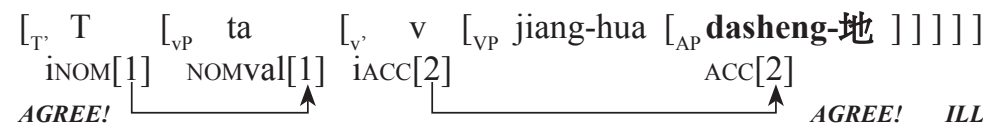

Note, furthermore, that even if we were to assume little v did not need to bear ACC in this structure, the case needs of the 地-marked adverb could not be met by NOM. Dasheng-地 is positioned below the subject, which is valued for NOM; the probegoal relation for NOM will extend no further than the subject (56):

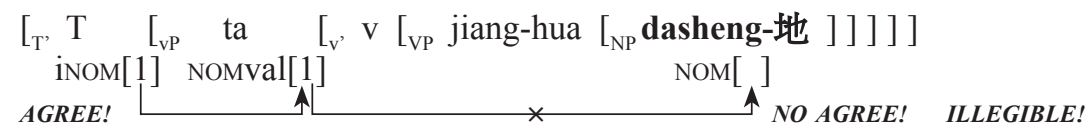

The only option for "rescuing" the structure in (55) is to raise dasheng-地 to a position between $\mathrm{T}$ and the subject - for example, the vP edge. In this sentencemedial site, it will be able to participate in the agreement relation between $\mathrm{T}$ and the nominative subject, resulting a legible feature (57): ${ }^{13}$

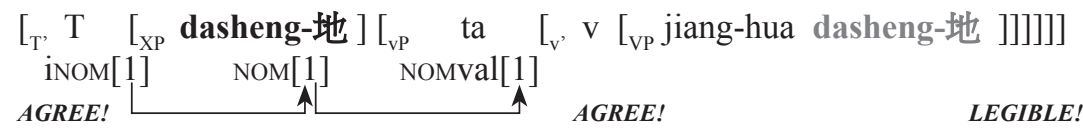

Hence, we derive the sentence medial position of AP-地.

Given the discussion of (56), we might wonder about examples like (39a,d), repeated below as $(58 \mathrm{a}, \mathrm{b})$ :

(58) a. Ta chang minge hen dasheng.

he sing folk songs very loudly

'He sings folk songs loudly.'

13 Examples (14a,b) (repeated below in opposite order) demonstrate that hen dasheng 'very loudly' can raise to a preverbal, sentence-medial position even in the absence of -地. Hence, the movement postulated in (57) requires no special stipulations:

(i) a. Ta chang minge hen dasheng.

3SG sing folk songs very loud

'He sings folk songs loudly.'

b. Ta hen dasheng chang minge 
b. Ta huida wenti hen naixin.

he answer question very patiently

'He answers questions patiently.'/'He answers questions with patience.'

The presence of the surface object minge 'folk songs' in (58a) might seem to intercept the probe-goal relation between little $\mathrm{v}$ and dasheng, leaving the latter unagreed (59):

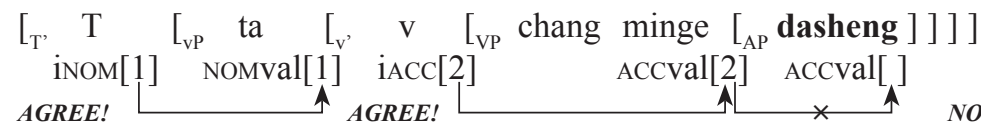

NO AGREE!

I assume that in the case of conventionalized verb-object combinations like this "sing (folk) songs", "ask questions", etc. - the Mandarin object can incorporate into the verb, analogously to what occurs with English V-N combinations like play chess or sing soprano. In incorporation, the case requirements on the surface object are suppressed (Baker 1988). The picture therefore becomes as in (60): ${ }^{14}$

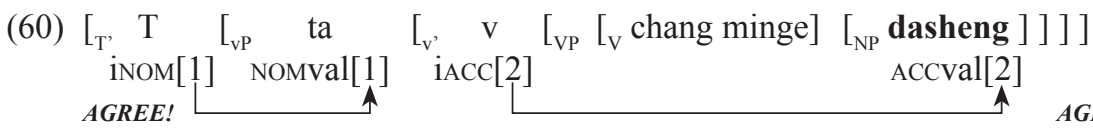

AGREE!

This supplies the last step required under the line of reasoning above. Recall, we saw that a movement account of AP-地 adverbs would reconcile their surface medial position in generics with the low position required under Diesing's mapping hypothesis. We then inquired why movement is required with such forms - why low complement position was forbidden to AP-地 adverbs? The proposed answer hinges on the apparent nominal character of manner adverbs that can remain in the low position and the effect of affixing -地. The suggestion is that -地 creates a case-concordial phrase of the element to which it affixes, forcing it to occupy a position in which case concord is possible. This requires sentence-medial position in Mandarin, low sentence-final position is not an option.

14 An anonymous SCL reviewer notes potential questions for this proposal arising from examples like (i), where the boldfaced object nominal is considerably more elaborate than minge 'folksongs' in (59), and (presumably) a far less likely candidate for incorporation:

(i) Ta huida xuesheng ketangshang de wenti yixiang hen xiaoxin.

3SG answer student in-class DE questions always very careful

'He always answers student questions in class very carefully.'

I do not have a satisfactory answer. But I do note that when such examples are questioned with weishenme 'why' as in (ii), the VP is plainly understood in the generic way typical of incorporated structures. That is, the object is understood as contributing to the formation of a complex predicate:

(ii) Ta weishenme huida xuesheng ketangshang de wenti yixiang hen xiaoxin? 3SG why answer student in-class DE questions always very careful 'Why is he always-very-carefully-answering-student-questions-in-class?' (rather than paying attention to departmental duties)

This suggests that current notions of incorporation may require extension. 
4.6 Mandarin nominal 的 and purely adjectival adverbs

Larson (2009) argues that the nominal DE (的) appearing in (61a,b) should also be considered a concordializing element in Mandarin (62):

(61) a. Hen dasheng de ren zou le. very loud DE person leave PERF

'A/the loud person left.'

b. Ta mai le piaoliang de yifu.

3SG buy ASP pretty DE clothes

'He bought some attractive clothes.'

(62)

$$
\begin{gathered}
{[\mathrm{AP} \alpha-\text { 的] }} \\
\text { CASE[ ] }
\end{gathered}
$$

On this view, the analysis of case relations in $(61 a, b)$ is as in $(63 a, b)$, respectively. In (63a) dasheng-的 'loud' agrees with the subject in nominative case, much like the prenominal Icelandic elements in (42). In (63b), piaoliang-的 'pretty' agrees with the direct object in accusative case, much like the prenominal German elements in (51):

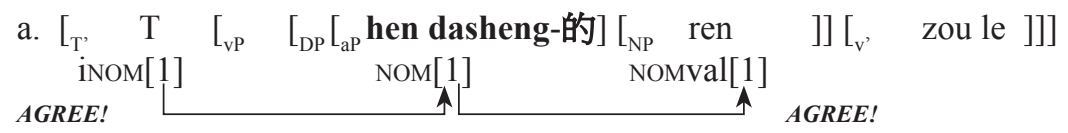
b. $\left[\left[_{\mathrm{T}}, \mathrm{T}\left[\left[_{\mathrm{vP}}\right.\right.\right.\right.$ ta $\left[{ }_{\mathrm{v}}, \mathrm{V} \quad\left[\mathrm{VP}\right.\right.$ mai $\left[{ }_{\mathrm{DP}}\left[\left[_{\mathrm{XP}}\right.\right.\right.$ piaoliang-的 $]\left[_{\mathrm{NP}}\right.$ yifu $\left.\left.\left.\left.\left.]\right]\right]\right]\right]\right]$ AGREE! $\uparrow$

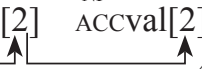

Observe the close resemblance in agreement relations between (63a) with nominal DE (的) and (57) (repeated below) with adverbial DE (地):

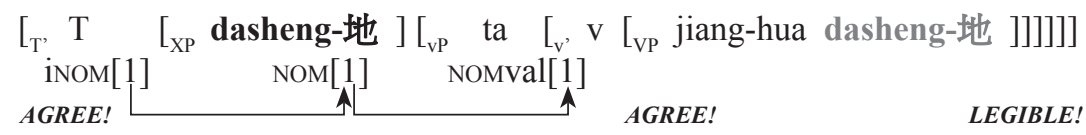

This proposal sheds light, I believe, on a final distributional question that arises with Mandarin 地-marked forms and also suggests a broader point about Mandarin adjectivals. We have seen that Mandarin manner adverbs with a "nominal core" are licensed in final position without $\mathrm{DE}$ (地) and can also front to the $\mathrm{vP}$ edge without DE (64)..$^{15}$ By contrast, "purely adjectival" forms of the shape AA-DE

15 Having DE is usually preferred. However Chi-hang Cheung (personal communication) pointed out to me that some Mandarin examples like (ib) actually prefer DE to be absent.

(i) a. Ta chang ge hen hao-ting.

he sing song very good-listen

'He sings very well.'

b. Ta (hen) hao-ting (*-de) chang ge.

he very good-listen-DE sing song

Intended: 'He sang well.'/'He sings well.' 
or AABB-DE never occur sentence-finally and never occur sentence-medially without DE (地) (65):

(64) a. Ta chang minge hen dasheng.

3SG sing folk songs very loud

'He sings folk songs loudly.'

b. Ta hen dasheng (de) chang minge.

(65) a. *Ta likai qiaoqiao (de).

$3 \mathrm{SG}$ leave quiet

'He leaves quietly.'

b. Ta qiaoqiao *(de) likai.

3SG quietly DE leave

'He leaves quietly.'/'He left quietly.'

On the account presented here, the unacceptability of purely adjectival forms sentence-finally with DE (65a) follows from their concordial status, which is inappropriate for that position. The unacceptability of purely adjectival forms sentence-finally without DE (65a) follows from their non-nominal status - their inability to be case licensed in that site. The acceptability of purely adjectival forms sentence-medially with DE (65b) follows from their concordial status, which is appropriate for that position. The unacceptability of purely adjectival forms sentence medially without DE (65b) is not self-evident, however. ${ }^{16}$

16 An anonymous SCL reviewer notes the contrast in (ia,b). Whereas manmande 'slowly' with adverbial DE (地) is forbidden in final position, as we have observed, manmande 'slow' with adjectival DE (的) is allowed:

(i) a. *Ta shuohua (yixiang) manmant地.

3SG speak always slow-DE (ADVERBIAL)

'He (always) speaks slowly.'

b. Ta shuohua (yixiang) manman的.

I suggest that the structure and interpretation of (ib) is actually rather different from (ia), essentially as in (ii), where $\mathrm{V}$ is a null copula and where $\mathrm{N}$ is a null noun interpreted as "one".

(ii) $\mathrm{Ta}$ shuohua (yixiang) $\mathrm{V} \quad\left[{ }_{\mathrm{NP}} \operatorname{manman}\right.$ 的 $\mathrm{N}$ ]

3sG speak always COP slow-DE ONE

'His speaking (always) is a slow one.'

Adjectival DE (的) in (ii) is thus roughly counterpart to long-form marking on Russian attributive adjectives as analyzed by Babby $(1973,1975)$; it is invariably the sign of attributive modification. In the case of final predicative adjectives like (ib), 的 indicates the presence of a null noun.

This proposal analyzes the initial sequence ta shuohua as a nominal 'his speaking' rather than a subject-main verb sequence 'he speaks'; it also postulates a null verb before AP-的. The same reviewer notes support for both views. Modals occur before the main verb (iiia,b), but can occur after shuohua in (iv). Also weishenme 'why' occurs before the main verb (va,b) but can occur after shuohua in (vi). Both suggest that shuohua is not the main verb.

(iii) a. Ta yinggai zoulu.

3SG should walk

'He should walk.'

b. *Ta zoulu yinggai. 
In Icelandic and German, and indeed in many other languages, concordial behavior seems to be a basic feature of adjectives. That is, adjectives as a category quite generally show agreement with $\mathrm{N}$ in case, $\varphi$-features, etc. with no further supplementation. By contrast, the pattern in (65b) suggests that Mandarin adjectives behaving as verbal modifiers can function concordially only if they are affixed with an explicit concordializing element DE (地). Simply being an adjectival stem qiao(qiao) 'quiet' is not sufficient to obtain case by concord.

Notice now that if Larson (2009) is correct, the very same fact holds of Mandarin adjectives behaving as nominal modifiers (66); they too can function concordially only if they are affixed with the explicit concordializing element DE (的). ${ }^{17}$
a. Hen dasheng *(de) ren zou le. very loud DE person leave PERF
'A/the loud person left.'
b. Ta mai le piaoliang*(de) yifu.
3SG buy ASP pretty DE clothes
'He bought some attractive clothes.'

This strongly suggests that concordiality is not basic to the featural makeup of Mandarin adjectives but rather is something that must (or can) be "added on" to them in the course of derivation, whether A is functioning as an adverbial modifier in the $\mathrm{vP}$ or as an adjectival modifier in the DP domain. It is then worth pondering

(iv) women shuohua yinggai manman的, cai bu hui shuocuo hua. 2PL speak should slow then not enable wrong speech 'Our speaking should be slow, so as not to say the wrong things.'

(v) a. Ta weishenme chang ge?

3sG why sing song

'Why did he sing?'

b. * Ta chang ge weishenme.

(vi) Ta shuohua weishenme manman的?

3sG speak why slow

'Why is his speaking slow?'

Note that the dual positioning possible for weishenme in (viia,b) indicates that hen dasheng 'loud' must be accorded a dual analysis as both a final manner adverb and a predicate adjective. In (viia) weishenme occurs preverbally, confirming changge as the main verb. Hen dasheng is thus a manner adverb. In (viib) weishenme occurs after changge, confirming that the latter is not the main verb.

(vii) a. Ta weishenme chang ge hen dasheng?

3SG why sing song very loud

'Why does he sing loudly?' (given that he speaks softly)

b. Ta chang ge weishenme hen dasheng?

3SG sing song why very loud

'Why is his singing loud?' (i.e., why does it have that property)

17 Mandarin adjectival modifiers are known drop DE (的) and appear as "bare modifiers" in certain well-studied instances. The factors bearing on this are discussed by Sproat and Shih (1991), Sio (2006), among many others. 
whether concordiality is basic to the featural makeup of adjectives in any language and whether in fact all languages do not also involve concordializing elements, which simply fail to surface in many. If this conjecture proves correct, then Mandarin grammar, in its exquisite analyticity, reveals to us something significant about the internal composition of lexical forms and about the nature of agreement and concord generally in natural language.

\section{Acknowledgments}

I thank audiences at Peking University and the 27th North American Conference on Chinese Linguistics (NACCL 27), where earlier versions of this material were present. I am grateful to James Huang and two anonymous Studies in Chinese Linguistics reviewers for critique and helpful suggestions on the analysis proposed here. I am particularly indebted to Chi-hang Cheung, Sophia Kao, Yaobin Liu, Yu-an Lu, Chih-hsiang Shu, Hongchen Wu, and Chong Zhang for indispensable help with judgments on the Mandarin data in this paper.

\section{References}

Alexiadou, Artemis. 1997. Adverb placement: A case study in antisymmetric syntax. Amsterdam: John Benjamins Publishing Company.

Anderson, Stephen. 1992. A-morphous morphology. Cambridge, UK: Cambridge University Press.

Babby, Leonard. H. 1973. The deep structure of adjectives and participles in Russian. Language 49(2). 349-360.

Babby, Leonard. H. 1975. A transformational grammar of Russian adjectives. The Hague: Mouton.

Baker, Mark C. 1988. Incorporation: A theory of grammatical function changing. Chicago: University of Chicago Press.

Capen, Carole Jamieson. 1995. Chiquihuitlán Mazatec postverbs: The role of extension in incorporation. In Eugene Casad (ed.), Cognitive linguistics in the redwoods: The expansion of a new paradigm in linguistics, 943-969. Berlin: Mouton de Gruyter.

Chierchia, Gennaro. 1995. Individual-level predicates as inherent generics. In Gregory N. Carlson \& Francis Jeffry Pelletier (eds.), The generic book, 176-223. Chicago: University of Chicago Press.

Chomsky, Noam. 1995. The minimalist program. Cambridge, MA: MIT Press.

Cinque, Guglielmo. 1999. Adverbs and functional heads: Across-linguistic approach. New York: Oxford University Press.

Condoravdi, Cleo. 1989. The middle: Where semantics and morphology meet. In MIT working papers in linguistics 11. 18-30.

Corbett, Greville G. 1987. The morphology/syntax interface: Evidence from possessive adjectives in Slavonic. Language 63(2). 299-344.

Diesing, Molly. 1992. Indefinites. Cambridge, MA: MIT Press.

Drachman, Gaberell \& Angeliki Malikouti-Drachman. 1992. Stress and Greek compounding. Unpublished manuscript, University of Salzberg. 
Emonds, Joseph. 1976. A transformational approach to English syntax: Root, structure preserving, and local transformations. New York: Academic Press.

Emonds, Joseph. 1985. A unified theory of syntactic categories. Dordrecht: Foris.

Ernst, Thomas. 2002. The syntax of adjuncts. Cambridge, UK: Cambridge University Press.

Ernst, Thomas. 2014. Adverbial adjuncts in Mandarin Chinese. In Huang, C-T James, Y.-H. Audrey Li \& Andrew Simpson (eds.), The handbook of Chinese linguistics. 49-72. New York: John Wiley \& Sons, Inc.

Herburger, Elena. 2000. What counts. Cambridge, MA: MIT Press.

Huang, C.-T. James. 1992. Complex predicates in control. In Richard Larson, Sabine Iatridou \& Utpal Lahiri (eds.), Control and grammar. 109-147. Dordrecht: Kluwer.

Huang, C-T James, Y.-H. Audrey Li \& Yafei Li. 2009. The syntax of Chinese. Cambridge, UK: Cambridge University Press.

Kester, Ellen-Petra. 1996. The nature of adjectival inflection. Utrecht: OTS.

Laenzlinger, Christopher. 1996. Adverb syntax and phrase-structure. In Anna-Maria di Sciullo (ed.), Configurations: Essays on structure and interpretation. Somerville, MA: Cascadilla Press.

Langacker, Ronald W. (ed.). 1979. Studies in Uto-Aztecan grammar, Vol. 2, Modem Aztec grammatical sketches. Dallas, TX: Summer Institute of Linguistics and the University of Texas at Arlington.

Larson, Richard K. 2004. On sentence-final adverbs and 'scope' (Reprinted in Larson 2014).

Larson, Richard K. 2009. Chinese as a reverse Ezafe language. Yuyanxue Luncong [Essays on linguistics] 39. 30-85.

Larson, Richard K. 2014. On shell structure. London: Routledge.

Li, Charles \& Sandra Thompson. 1981. Mandarin Chinese: A functional reference grammar. Berkeley: University of California Press.

Li, Yen-Hui Audrey. 1985. Abstract case in Chinese. Los Angeles, CA: USC dissertation.

Li, Yen-Hui Audrey. 1990. Order and constituency in Mandarin Chinese. Dordrecht: Kluwer.

McConnell-Ginet, Sally. 1994. On the non-optionality of certain modifiers. In Mandy Harvey \& Lynn Santelmann (eds.), Proceedings from the Semantics and Linguistic Theory IV Conference. 23-250. Ithaca: DMLL Publications, Cornell University.

Pesetsky, David \& Esther Torrego. 2007. The syntax of valuation and the interpretability of features. In Simin Kairimi, Vida Samiian \& Wendy K. Wilkins (eds.), Phrasal and clausal architecture: Syntactic derivation and interpretation. 262-294. Amsterdam: John Benjamins Publishing Company.

Rivero, María-Luisa. 1992. Adverb incorporation and the syntax of adverbs in Modern Greek. Linguistics and Philosophy 15(3). 289-331.

Roberts, Ian. 1987. The representation of implicit and dethematized subjects. Berlin: De Gruyter Mouton. 
Sio, Joanna Ut-seong. 2006. Modification and reference in the Chinese nominal. Utrecht: LOT.

Smirniotopoulos, Jane C. \& Brian D. Joseph. 1997. On so-called "adverbincorporation" in Modern Greek. In Gaberell Drachman, Angeliki MalikoutiDrachman, Ioannis Fykias \& Chrysoula Klidi (eds.), Greek linguistics '95. Proceedings of the 2nd International Conference on Greek Linguistics, 117-128. Graz: Neubauer Verlag.

Sproat, Richard \& Chilin Shih. 1991. The cross-linguistic distribution of adjectival ordering restrictions. In Carol Georgeopoulos \& Roberta Ishihara (eds.), Interdisciplinary approaches to language: Essays in honor of S.Y. Kuroda, 565593. Dordrecht: Kluwer.

Stroik, Thomas. 1990. Adverbs as V-sisters. Linguistic Inquiry 21(4). 654-661.

Stroik, Thomas. 1992a. Adverbs and antecedent contained deletions. Linguistics 30(2). 375-380.

Stroik, Thomas. 1992b. On the distribution of temporal and locative NP adverbials. The Linguistic Review 9(3). 267-284.

Tang, C.-C. Jane. 1990. Chinese phrase structure and the extended X'-theory. Ithaca, NY: Cornell University dissertation.

Mailing address: Department of Linguistics, Stony Brook University, Stony Brook, NY 11794-4376, USA

Email: $\quad$ richard.larson@stonybrook.edu

Received: $\quad$ August 24, 2017

Accepted: $\quad$ October 16, 2017 


\title{
漢語 “AP-地” 副詞
}

\author{
Richard K. Larson
}

石溪大學

\section{提要}

漢語方式副詞, 比如：“大聲”, 既可出現在句子中間的位置, 也可出現在句子末 尾; 但是, 由副詞與副詞標記 “地” 組成的像 “快快地” 這樣的副詞短語, 則只 能出現在句子中間的位置。傳統的附接分析以及Cinque (1999)提出的功能投射層級 順序, 並不能很全面地解釋漢語中 “AP-地” 的句法表現。本文提出, 漢語方式副 詞在句法結構上一般是附在 V 補語結構內部較低的位置, 而由 “地” 作為 “協調成 分” 的特性所引發的強制移位, 則是方式副詞能處於動詞前/中間位置的原因。

\section{關鍵詞}

漢語, 方式副詞, 格, 協調 